\title{
Effect Clinical Research Paper Effect of metformin on kidney function in patients with type 2 diabetes mellitus and moderate chronic kidney disease
}

\author{
Wei-Hao Hsu',2, Pi-Jung Hsiao ${ }^{1,3}$, Pi-Chen Lin', Szu-Chia Chen ${ }^{2,3,4,5}$, Mei-Yueh \\ Lee $^{1,2,3,4}$ and Shyi-Jang Shin ${ }^{1,3,6}$ \\ ${ }^{1}$ Division of Endocrinology and Metabolism, Department of Internal Medicine, Kaohsiung Medical University Hospital, \\ Kaohsiung Medical University, Kaohsiung, Taiwan \\ ${ }^{2}$ Department of Internal Medicine, Kaohsiung Municipal Hsiao-Kang Hospital, Kaohsiung Medical University, Kaohsiung, \\ Taiwan \\ ${ }^{3}$ Faculty of Medicine, College of Medicine, Kaohsiung Medical University, Kaohsiung, Taiwan \\ ${ }^{4}$ Graduate Institute of Clinical Medicine, College of Medicine, Kaohsiung Medical University, Kaohsiung, Taiwan \\ ${ }^{5}$ Division of Nephrology, Department of Internal Medicine, Kaohsiung Medical University Hospital, Kaohsiung Medical \\ University, Kaohsiung, Taiwan \\ ${ }^{6}$ Center for Lipid and Glycomedicine Research, Kaohsiung Medical University, Kaohsiung, Taiwan
}

Correspondence to: Mei-Yueh Lee, email: lovellelee@hotmail.com

Keywords: metformin; diabetes mellitus; chronic kidney disease; renal function decline; estimated glomerular filtration rate

Received: September 12, 2017

Accepted: December 04, 2017

Published: December 17, 2017

Copyright: Hsu et al. This is an open-access article distributed under the terms of the Creative Commons Attribution License 3.0 (CC BY 3.0), which permits unrestricted use, distribution, and reproduction in any medium provided the original author and source are credited.

\section{ABSTRACT}

Background: Impaired renal function can lead to the accumulation of metformin, and elevated concentrations of metformin have been associated with lactic acidosis. The aim of this study was to evaluate the effect of continuous metformin treatment in patients with type 2 diabetes mellitus (DM) and moderate chronic kidney disease (CKD) (estimated glomerular filtration rate (eGFR) $30-0 \mathrm{ml} / \mathrm{min} / 1.73 \mathrm{~m}^{2}$ ) on renal function.

Methods: A total of the 616 patients were enrolled from the research database of Kaohsiung Medical University Hospital from January 1 to 2009 and December 31, 2013. The patients were divided into two groups: those who continued metformin treatment (continuation group; $n=484$ ), and those who discontinued metformin treatment for at least 100 days (interruption group; $n=132$ ).

Results: The slope of eGFR in the metformin interruption group was statistically lower than that in the metformin continuation group $(0.75 \pm 0.76$ vs. $-1.32 \pm 0.24$ $\mathrm{mL} / \mathrm{min} / 1.73 \mathrm{~m}^{2} /$ year, $p=0.0007$ ). After adjusting for baseline covariates in the multivariate linear regression analysis, the continuation of metformin (unstandardized coefficient $\beta,-2.072 ; 95 \%$ confidence interval, $-3.268-\mathbf{0 . 8 7 6}$ ) was a risk factor for the patients with DM and moderate CKD.

Conclusions: Metformin may have an adverse effect on renal function in patients with type 2 DM and moderate CKD.

\section{INTRODUCTION}

Metformin is an oral hypoglycemic agent of the biguanide class that lowers blood glucose level mainly by decreasing hepatic glucose production and improving insulin sensitivity of the peripheral tissues by increasing peripheral glucose uptake and utilization [1]. Metformin was approved by the U.S. Food and Drug Administration
(FDA) In 1994, and it is generally recommended as the first-line pharmacological agent in management guidelines for patients with type 2 diabetes mellitus (DM) because of its low cost, safety, and association with a reduction in the risk of cardiovascular events [2].

The use of metformin is contraindicated in men and women with serum creatinine concentrations of $1.5 \mathrm{mg} / \mathrm{dL}$ or higher and $1.4 \mathrm{mg} / \mathrm{dL}$ or higher, respectively, 
due to the risk of the life-threatening complication, lactic acidosis. Risk factors including severe dehydration (i.e., reduced tissue perfusion), congestive heart failure, sepsis, shock, hypoxia, hepatic impairment, advanced age, and excessive alcohol intake may also increase the risk of metformin-associated lactic acidosis $[1,3,4]$. Metformin is primarily excreted unchanged by the kidney, and renal impairment may cause the accumulation of metformin leading to an elevated metformin concentration, and this has been proposed to lead to lactic acidosis [5]. The overall incidence of lactic acidosis in metformin users ranges from approximately 3 per 100,000 person-years to 10 per 100,000 person-years, which is similar to the background rate in patients with type 2 DM [6].

In April 2016, the FDA revised their warning with regards to metformin use in patients with impaired kidney function, defining the renal impairment according to estimated glomerular filtration rate (eGFR). The revised guidelines stated that the use of metformin is only absolutely contraindicated in patients with severe chronic kidney disease $(\mathrm{CKD})\left(\mathrm{eGFR}<30 \mathrm{ml} / \mathrm{min} / 1.73 \mathrm{~m}^{2}\right)$. Therefore, patients with moderate CKD (eGFR 30-59 ml/min/1.73 m²) are eligible to receive metformin. A previous study reported that the use of metformin in patients with type 2 DM and advanced CKD was associated with a significantly increased risk of all-cause mortality compared with non-users [7]. This raises the concern that a decline in renal function in patients with moderate $\mathrm{CKD}$ receiving metformin may increase the risk of toxicity to metformin. The purpose of this study was to evaluate the effect of continuous metformin treatment on renal function in patients with type $2 \mathrm{DM}$ and moderate CKD (eGFR 30-60 ml/min/1.73 $\mathrm{m}^{2}$ ).

\section{RESULTS}

We identified 23,297 patients who were diagnosed with type $2 \mathrm{DM}$ in the Kaohsiung Medical University Hospital (KMUH) research database between January 1, 2009 and December 31, 2013, of whom 616 met our inclusion and exclusion criteria. One hundred and thirtytwo patients were classified to the metformin interruption group, and 484 to the metformin continuation group. Several differences were noted in baseline characteristics between the two groups (Table 1). The patients in the metformin interruption group were younger, had a higher level of glycated hemoglobin (HbAlc), increased use of anti-diabetic drugs including $\alpha$-glucosidase inhibitors, dipeptidyl peptidase-4 (DDP-4) inhibitors and insulin, and increased use of statins compared to those in the metformin continuation group.

The eGFR slopes in the metformin interruption and continuation groups were $0.75 \pm 0.76$ and $-1.32 \pm$ $0.24 \mathrm{~mL} / \mathrm{min} / 1.73 \mathrm{~m}^{2} /$ year, respectively (Figure 1), and the eGFR slope was significantly lower in metformin continuation group $(p=0.0007)$. In univariate linear regression analysis (Table 2), the risk of a decline in the eGFR slope was associated with metformin continuation (unstandardized coefficient $\beta,-2.072 ; 95 \%$ confidence interval (CI), -3.268- -0.876), high serum low-density lipoprotein cholesterol (LDL-C) (unstandardized coefficient $\beta,-0.024 ; 95 \% \mathrm{CI},-0.039--0.010)$, high HbA1c (unstandardized coefficient $\beta,-0.394 ; 95 \% \mathrm{CI}$, $-0.641--0.146$ ), low baseline eGFR (unstandardized coefficient $\beta, 1.697 ; 95 \%$ CI, 0.625-2.770), high uric acid level (unstandardized coefficient $\beta,-0.454 ; 95 \% \mathrm{CI}$, $-0.766--0.142$ ), high urinary albumin creatinine ratio (UACR) (unstandardized coefficient $\beta,-1.339$; 95\% CI, $-1.998--0.679)$, use of angiotensin-converting enzyme inhibitors (ACEIs) and/or angiotensin receptor blockers (ARBs) (unstandardized coefficient $\beta,-3.667 ; 95 \% \mathrm{CI}$, $-5.30--2.034)$, and the use of cyclooxygenase-1 (COX-1) or COX-2 inhibitors (unstandardized coefficient $\beta$, 1.407 ; $95 \% \mathrm{CI},-0.641--0.146)$. In multivariate linear regression analysis (Table 2), the risk of a decline in the eGFR slope was associated with metformin continuation (unstandardized coefficient $\beta,-2.339 ; 95 \% \mathrm{CI},-3.632-$ -1.047), high serum LDL-C (unstandardized coefficient $\beta,-0.025 ; 95 \% \mathrm{CI},-0.041--0.008)$, high HbA1c (unstandardized coefficient $\beta,-0.321 ; 95 \% \mathrm{CI},-0.593-$ -0.049 ), low baseline eGFR (unstandardized coefficient $\beta, 2.599 ; 95 \%$ CI, 1.399-3.799), high uric acid level (unstandardized coefficient $\beta,-0.480 ; 95 \% \mathrm{CI},-0.777$ - -0.184 ), high UACR (unstandardized coefficient $\beta$, $-1.133 ; 95 \% \mathrm{CI},-1.875--0.391)$, and the use of ACEIs and/or ARBs (unstandardized coefficient $\beta,-3.593$; 95\% CI, $-5.487--1.698)$.

\section{DISCUSSION}

In this retrospective cohort study, the patients with type 2 DM who received metformin therapy for at least 6 months had a greater decline in eGFR if they continued metformin therapy compared to those who discontinued metformin treatment for at least 100 days. The continuation of metformin therapy was significantly associated with a decline in renal function in the patients with DM and moderate CKD. Other risk factors for a decline in renal function included high serum LDL-C, high $\mathrm{HbA1c}$, low baseline eGFR, high uric acid level, high UACR, and the use of ACEIs and/or ARBs.

Diabetic nephropathy (DN) is a clinical syndrome characterized by persistent albuminuria confirmed on at least two occasions 3-6 months apart, a progressive decline in glomerular filtration rate, and elevated arterial blood pressure [8]. DN is a microvascular complication of type 2 DM. A previous study reported that metformin was beneficial for improving albuminuria compared with glibenclamide in patients with DN [9]. In addition, an animal study showed that metformin suppressed diabetes-induced podocyte loss in DN by preventing oxidative injury [10]. Recently, Samira et. reported no increase in the risk of acute kidney injury in patients receiving metformin compared to those without metformin treatment by baseline eGFR [11]. However, 
Table 1: Baseline clinical characteristics of patients among study groups

\begin{tabular}{|c|c|c|c|}
\hline Characteristics & $\begin{array}{l}\text { Metformin interruption } \\
\qquad(n=132)\end{array}$ & $\begin{array}{l}\text { Metformin continuation } \\
\qquad(n=484)\end{array}$ & $P$-value \\
\hline Age (year) & $65.9 \pm 9.7$ & $68.3 \pm 10.2$ & $0.0190^{*}$ \\
\hline Male gender (\%) & $63(47.7)$ & $212(43.8)$ & 0.4213 \\
\hline \multicolumn{4}{|l|}{ Comorbidities of baseline } \\
\hline Hypertension (\%) & $53(40.2)$ & $171(35.3)$ & 0.3074 \\
\hline Ischemic heart disease (\%) & $9(6.8)$ & $15(3.1)$ & 0.0503 \\
\hline Heart failure (\%) & $2(1.5)$ & $6(1.2)$ & $0.6824^{\mathrm{a}}$ \\
\hline Categories of UACR & & & 0.1298 \\
\hline UACR <30 mg/dL (\%) & $67(50.8)$ & 278 (57.4) & \\
\hline UACR 30-299 mg/dL (\%) & $47(35.6)$ & $129(26.7)$ & \\
\hline UACR $\geq 300$ mg/dL (\%) & $18(13.6)$ & $77(15.9)$ & \\
\hline \multicolumn{4}{|l|}{ Laboratory parameters } \\
\hline Fasting glucose (mg/dL) & $142.3 \pm 49.4$ & $147.4 \pm 52.2$ & 0.4087 \\
\hline Triglyceride (mg/dL) & $177.5 \pm 126.5$ & $156.8 \pm 114.8$ & 0.0730 \\
\hline Total cholesterol (mg/dL) & $173.9 \pm 42.9$ & $176.8 \pm 43.0$ & 0.4976 \\
\hline $\mathrm{LDL}-\mathrm{C}(\mathrm{mg} / \mathrm{dL})$ & $99.5 \pm 34.8$ & $101.1 \pm 33.6$ & 0.6475 \\
\hline HDL-C (mg/dL) & $38.9 \pm 12.6$ & $41.0 \pm 11.9$ & 0.0877 \\
\hline $\operatorname{HbA1C}(\%)$ & $8.3 \pm 1.8$ & $7.9 \pm 2.0$ & $0.0239^{*}$ \\
\hline Baseline eGFR $\left(\mathrm{mL} / \mathrm{min} / 1.73 \mathrm{~m}^{2}\right)$ & $48.2 \pm 8.2$ & $49.4 \pm 7.7$ & 0.0999 \\
\hline Uric acid (mg/dL) & $7.2 \pm 2.1$ & $7.1 \pm 1.8$ & 0.5736 \\
\hline \multicolumn{4}{|l|}{ Anti-hypertensive drugs } \\
\hline ACEI and/or ARB (\%) & $118(89.4)$ & $437(90.3)$ & 0.7602 \\
\hline Calcium channel blocker (\%) & $95(72.0)$ & $364(75.2)$ & 0.4494 \\
\hline$\beta$-blocker $(\%)$ & $65(49.2)$ & $206(42.6)$ & 0.1705 \\
\hline Diuretics (\%) & $81(61.4)$ & $308(63.6)$ & 0.6314 \\
\hline \multicolumn{4}{|l|}{ Anti-diabetic drugs } \\
\hline Sulfonylurea (\%) & $111(84.1)$ & $388(80.2)$ & 0.3081 \\
\hline Meglitinide(\%) & $26(19.7)$ & $67(13.8)$ & 0.0959 \\
\hline$\alpha$-glucosidase inhibitor (\%) & $38(28.8)$ & $91(18.8)$ & $0.0124^{*}$ \\
\hline Thiazolidinedione (\%) & $58(43.9)$ & $206(42.6)$ & 0.7768 \\
\hline DDP4 inhibitor (\%) & $75(56.8)$ & $218(45.0)$ & $0.0163^{*}$ \\
\hline Insulin $(\%)$ & $58(43.9)$ & $164(33.9)$ & $0.0329^{*}$ \\
\hline \multicolumn{4}{|l|}{ Lipid-lowering drugs } \\
\hline Statin $(\%)$ & $105(79.6)$ & $336(69.4)$ & $0.0222^{*}$ \\
\hline Fibrate (\%) & $37(28.0)$ & $101(20.9)$ & 0.0802 \\
\hline Niacin $(\%)$ & $2(1.5)$ & $8(1.7)$ & $0.9999^{\mathrm{a}}$ \\
\hline Cox-1+Cox-2 inhibitor (\%) & $38(28.8)$ & $153(31.6)$ & 0.5341 \\
\hline
\end{tabular}

Abbreviations. UACR, urinary albumin creatinine ratio; LDL-C, low-density lipoprotein cholesterol; HDL-C, high-density lipoprotein cholesterol; eGFR, estimated glomerular filtration rate; ACEI, angiotensin converting enzyme inhibitor; ARB, angiotensin II receptor blocker; DDP-4, dipeptidyl peptidase-4; Cox, cyclooxygenase.

${ }^{*} P<0.05$ compared with the group with metformin continuation. A $p$-value of $<0.05$ was considered to be statistically significant. 
in the present study, continuous metformin therapy was shown to worsen renal function in patients with DM and moderate CKD. A possible mechanism by which metformin increases the concentration of plasma lactate is that it inhibits mitochondrial respiration in tissues including the liver and muscles responsible for lactate removal [4, 12, 13]. Both the liver and kidney are major lactate-consuming organs, accounting for $\sim 60 \%$ and $\sim 30 \%$ of lactate removal, respectively $[14,15]$. Most of the lactate removal by the kidneys is through lactate metabolism rather than excretion [15], and impaired renal function may decrease the ability of the kidneys to metabolize an increase in lactate caused by metformin. A previous clinical study demonstrated that metformin users with a renal function of eGFR $<60 \mathrm{~mL} / \mathrm{min} / 1.73 \mathrm{~m}^{2}$ had a higher risk of lactic acidosis or elevated lactate concentrations [16]. Metforminassociated lactic acidosis can cause metabolic acidosis in patients with moderate CKD, and this has been shown to have a deleterious effect on renal function leading to a decline in eGFR and progression of CKD [17-19]. Several factors have been associated with the effect of metabolic acidosis on the decline in renal function, including ammonia-induced complement activation and acidosis-induced increased production of endothelin and aldosterone [19]. Taken together, all of these factors can cause tubule-interstitial injury and mediate a decline in eGFR [19], which may explain the inconsistent findings with regards to the effect of metformin on renal function.
Diabetic nephropathy is associated with oxidative stress caused by a persistent hyperglycemic state and increase in advanced glycation end products [20]. Hyperglycemia has been shown to alter redox equilibrium, which can then induce oxidative stress and cause kidney damage [21]. An animal study showed that the direct antioxidation and anti-inflammation effects of tanshinone II, a major diterpenoid derived from Salvia miltiorrhiza, alleviated renal histopathological injuries [22]. This suggests that oxidative stress mediates glucose-induced renal injury, and that alleviating oxidative injury may provide a renal protective effect. Hyperglycemia, inflammation, and cytokines have been reported to cause epigenetic modifications [23-25], including cytosine methylation of DNA (DNA methylation), histone posttranslational modifications and noncoding RNA [26]. Moreover, a review article showed that epigenetic processes are involved in the pathogenesis of DN [20]. Metformin has been shown to participate in DNA methylation by promoting DNA methyltransferase [27]. Hyperglycemia, oxidative stress, inflammation, cytokines, and gene and epigenetic modification may have complex interactions in which metformin may be involved, causing the progression of $\mathrm{DN}$ in patients with CKD.

Dyslipidemia has been reported to be a risk factor for adverse renal outcomes in apparently healthy men [28] and in patients with stage 3-5 CKD [29]. The pathophysiological link between dyslipidemia and CKD has been reported to involve accelerated atherosclerosis in the renal microcirculation and deposition of lipoprotein

\section{estimated glomerular filtration (eGFR) rate}

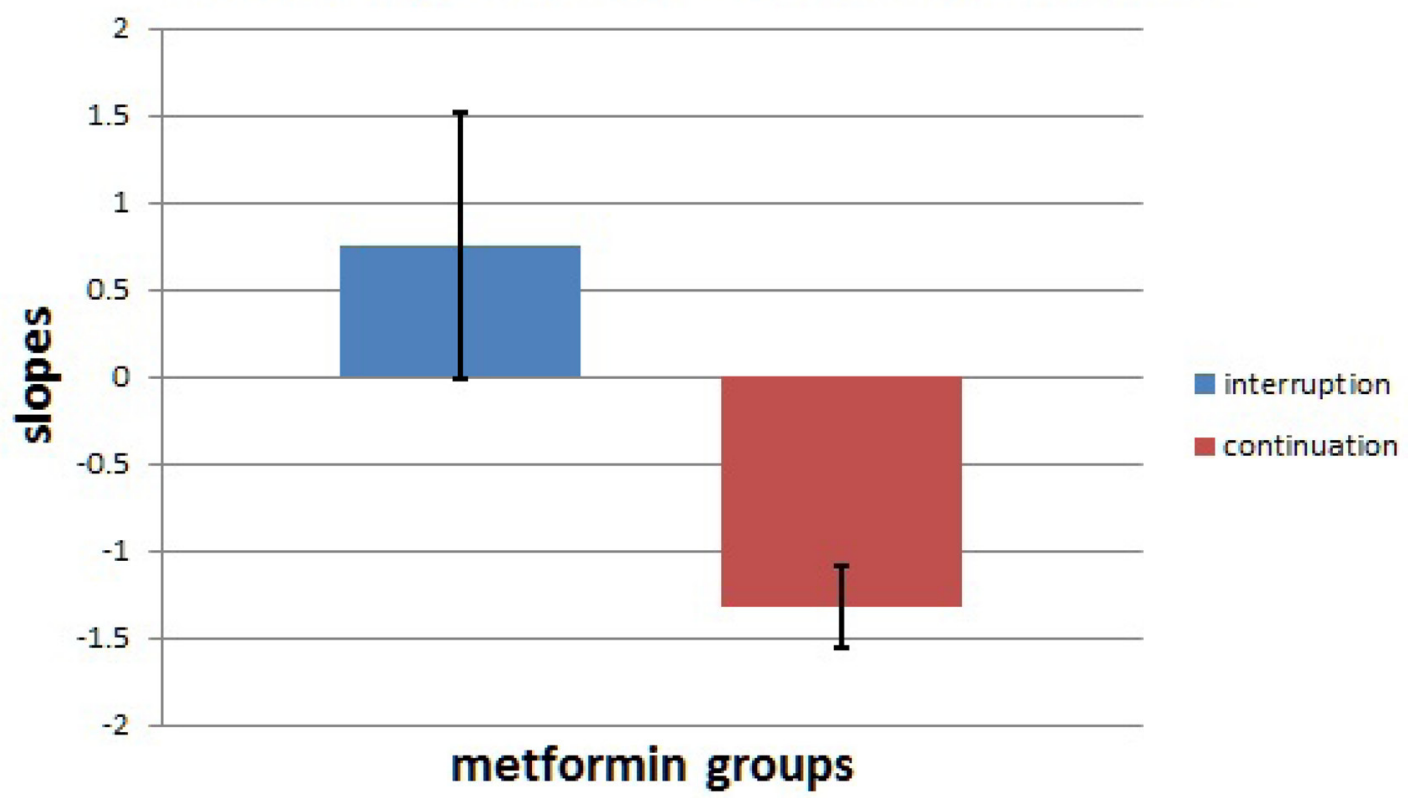

Figure 1: The estimated glomerular filtration rate (eGFR) slopes. The eGFR slopes in two groups with metformin interruption versus metformin continuation were $0.75 \pm 0.76$ and $-1.32 \pm 0.24 \mathrm{~mL} / \mathrm{min} / 1.73 \mathrm{~m}^{2} /$ year, respectively. The eGFR slope was lower in the group with metformin continuation than in the group with metformin interruption $(p=0.0007)$. 
Table 2: Determinants of eGFR slope using linear regression analysis

\begin{tabular}{|c|c|c|c|c|}
\hline \multirow[b]{2}{*}{ Characteristics } & \multicolumn{2}{|l|}{ Univariate } & \multicolumn{2}{|c|}{ Multivariate } \\
\hline & $\begin{array}{c}\text { Unstandardized coefficient } \\
\qquad \beta(95 \% \text { CI })\end{array}$ & $p$ & $\begin{array}{c}\text { Unstandardized } \\
\text { coefficient } \beta(95 \% \text { CI })\end{array}$ & $p$ \\
\hline $\begin{array}{l}\text { Metformin-continuation vs. } \\
\text { Metformin-interruption }\end{array}$ & $-2.072(-3.268,-0.876)$ & $0.0007^{*}$ & $-2.253(-3.549,-0.957)$ & $0.0007^{*}$ \\
\hline Age (per 1 year) & $-0.0004(-0.049,0.048)$ & 0.9858 & & \\
\hline Male vs. female & $0.611(-0.384,1.606)$ & 0.2294 & & \\
\hline Hypertension & $0.377(-0.652,1.406)$ & 0.4732 & & \\
\hline Ischemic heart disease & $2.367(-0.186,4.921)$ & 0.0697 & $2.481(-0.174,5.136)$ & 0.0676 \\
\hline Heart failure & $1.376(-2.999,5.750)$ & 0.5379 & & \\
\hline \multicolumn{5}{|l|}{ Laboratory parameters } \\
\hline Fasting glucose (per $1 \mathrm{mg} / \mathrm{dL}$ ) & $-0.006(-0.017,0.006)$ & 0.3383 & & \\
\hline Triglyceride (per 1 mg/dL) & $0.003(-0.001,0.007)$ & 0.1237 & & \\
\hline Total cholesterol (per $1 \mathrm{mg} / \mathrm{dL}$ ) & $-0.011(-0.023,0.000)$ & 0.0518 & $0.015(-0.004,0.035)$ & $0.0350^{*}$ \\
\hline LDL-C (per 1 mg/dL) & $-0.024(-0.039,-0.010)$ & $0.0011^{*}$ & $-0.039(-0.064,-0.015)$ & $0.0020^{*}$ \\
\hline HDL-C (per 1 mg/dL) & $0.035(-0.007,0.077)$ & 0.1070 & & \\
\hline HbA1C (per $1 \%$ ) & $-0.394(-0.641,-0.146)$ & $0.0019^{*}$ & $-0.333(-0.606,-0.06)$ & $0.0170^{*}$ \\
\hline $\begin{array}{l}\text { Baseline eGFR (per } 1 \\
\mathrm{~mL} / \mathrm{min} / 1.73 \mathrm{~m}^{2} \text { ) }\end{array}$ & $1.697(0.625,2.770)$ & $0.0020^{*}$ & $2.604(1.404,3.805)$ & $<.0001^{*}$ \\
\hline Uric acid (per $1 \mathrm{mg} / \mathrm{dL})$ & $-0.454(-0.766,-0.142)$ & $0.0045^{*}$ & $-0.482(-0.779,-0.185)$ & $0.0016^{*}$ \\
\hline UACR (per 1 mg/dL) & $-1.339(-1.998,-0.679)$ & $<.0001^{*}$ & $-1.176(-1.923,-0.429)$ & $0.0021^{*}$ \\
\hline \multicolumn{5}{|l|}{ Anti-hypertensive drugs } \\
\hline ACEI and/or ARB & $-3.667(-5.30,-2.034)$ & $<.0001^{*}$ & $-3.439(-5.393,-1.484)$ & $0.0006^{*}$ \\
\hline Calcium channel blocker & $-0.809(-1.944,0.326)$ & 0.1627 & & \\
\hline$\beta$-blocker & $-0.473(-1.470,0.525)$ & 0.3533 & & \\
\hline Diuretics & $-0.880(-1.905,0.144)$ & 0.0927 & $0.019(-1.184,1.221)$ & 0.9756 \\
\hline \multicolumn{5}{|l|}{ Anti-diabetic drugs } \\
\hline Sulfonylurea & $0.685(-0.577,1.946)$ & 0.2880 & & \\
\hline Meglitinide & $0.124(-1.260,1.508)$ & 0.8607 & & \\
\hline$\alpha$-glucosidase inhibitor & $0.603(-0.614,1.819)$ & 0.3318 & & \\
\hline Thiazolidinedione & $0.247(-0.754,1.248)$ & 0.6284 & & \\
\hline DDP4 inhibitor & $0.770(-0.221,1.760)$ & 0.1282 & & \\
\hline Insulin & $-0.379(-1.410,0.653)$ & 0.4722 & & \\
\hline \multicolumn{5}{|l|}{ Lipid-lowering drugs } \\
\hline Statin & $-0.156(-1.254,0.943)$ & 0.7812 & & \\
\hline Fibrate & $0.537(-0.650,1.725)$ & 0.3753 & & \\
\hline Niacin & $2.135(-1.782,6.052)$ & 0.2857 & & \\
\hline Cox-1+Cox-2 inhibitor & $1.407(0.342,2.472)$ & $0.0099^{*}$ & $1.21(0.021,2.399)$ & $0.0467^{*}$ \\
\hline
\end{tabular}

Covariates with $p$ value $<0.1$ in univariate analysis were entered into multivariate linear regression models. A $p$-value of $<0.05$ was considered to be statistically significant.

Abbreviation as Table 1.

in glomerular structures [30]. Several animal studies have shown that a high total cholesterol level can accelerate the rate of progression of kidney disease, and that a highcholesterol feeding can lead to macrophage infiltration and foam cell formation in rats $[30,31]$. In addition, a low
eGFR and high UACR at baseline have been associated with an increased risk of renal events in patients with type 2 DM [32]. Moreover, an elevated baseline HbA1c level has been reported to be a predictive factor for the progression of diabetic kidney disease [33]. In the present 
study, high serum LDL-C, high $\mathrm{HbA1c}$, low baseline eGFR, and high UACR were associated with a decline in renal function, which is consistent with previous studies.

There are several limitations to this study. First, this was a retrospective study that did not include randomization of the samples, and causation cannot be inferred from the results. Second, this study did not include all confounding factors (e.g. smoking, body weight, duration of DM, liver disease, alcohol abuse). Lastly, ACEIs and ARBs have been shown to reduce neointimal proliferation and vascular inflammation [34]. However, we found that the use of ACEIs or ARBs may have caused a decline in the eGFR slope. We did not evaluate the effects of these anti-hypertensive medications on renal outcomes because this study was not a clinical trial aimed at investigating the effect of medications. We also lacked sufficient data on the cumulative duration of exposure and defined daily dose, and the negative correlation between the use of anti-hypertensive medications and renal outcomes may have been due to selection bias.

In conclusion, continuous metformin treatment in patients with DM and moderate CKD was associated with a worsening in renal function. Metformin is currently indicated for diabetic patients with eGFR > $30 \mathrm{ml} / \mathrm{min} / 1.73 \mathrm{~m}^{2}$. However, according to the findings of the present study, metformin should be prescribed with caution for patients with DM and moderate CKD, and renal function should be followed closely in these patients.

\section{MATERIALS AND METHODS}

\section{Participants}

We performed this single-center retrospective cohort study at KMUH in Taiwan. The inclusion criteria were outpatients aged 18 years or older who had been diagnosed with type $2 \mathrm{DM}$ for $\geq 1$ year, an eGFR $30-60 \mathrm{ml} / \mathrm{min} / 1.73 \mathrm{~m}^{2}$, and at least 6 months of metformin treatment. The exclusion criteria were patients with type $1 \mathrm{DM}$, those who were pregnant, those with chronic glomerulonephritis, kidney transplant recipients, kidney infections, hydronephrosis, calculus of the kidney or ureter, cystitis, and those with bladder or renal cancer. A total of 616 patients were enrolled from the research database of KMUH between January 1, 2009 and December 31, 2013. The patients were divided into two groups according to whether they continuously received metformin treatment $(n=$ 484; metformin continuation group) or discontinued metformin treatment for at least 100 days ( $n=132$; metformin interruption group). All patients were followed up for at least one year. The study protocol was approved by the Institutional Review Board of Kaohsiung Medical University Hospital (KMUHIRBE(I)-20150185).

\section{Demographic, medical, and laboratory data collection}

Demographic and medical data including age, gender, comorbid conditions involving hypertension, ischemic heart disease, heart failure, cerebrovascular disease, peripheral arterial occlusive disease, and liver cirrhosis, and medications including anti-hypertensive agents, antidiabetic agents, lipid-lowering agents, non-steroidal antiinflammatory drugs, and selective COX-2 inhibitors were obtained from the research database of KMUH. Baseline laboratory data including blood fasting glucose, serum triglycerides, serum total cholesterol, serum LDL-C, serum high-density lipoprotein cholesterol, HbAlc, eGFR, serum creatinine, serum uric acid, and UACR were also collected. eGFR was calculated using the four-variable equation in the Modification of Diet in Renal Disease study.

\section{The eGFR slope determinants}

eGFR was recorded in the metformin continuation group until the point of the metformin interruption or the end of the study period. In the metformin interruption group, eGFR was measured from at least 100 days after discontinuing metformin until the point of re-starting metformin treatment or December 31, 2013. The rate of renal function decline was determined according to the eGFR slope, and defined as the regression coefficient between eGFR and time in units of $\mathrm{mL} / \mathrm{min} / 1.73 \mathrm{~m}^{2} /$ year, representing the change in the eGFR over time. At least four eGFR values were required to calculate the eGFR slope using regression coefficients between eGFR and time. A faster decline in renal function was indicated by a higher negative eGFR slope.

\section{Statistical analysis}

All statistical analyses were conducted using SAS statistical software version 9.2 (SAS Institute, Cary, NC, USA) for Windows. Data were expressed as mean \pm standard deviation. Between group differences were determined using the chi-square test for categorical variables and the independent $t$-test for continuous variables. A mixed-effect model analysis was used to evaluate the eGFR slopes between groups. A linear regression analysis was performed to determine the eGFR slopes. Covariates were entered into multivariate linear regression models if their $p$ value was $<0.1$ in univariate analysis. A $p$-value of $<0.05$ was considered to be statistically significant.

\section{Abbreviations}

diabetes mellitus (DM); chronic kidney disease (CKD); eGFR (estimated glomerular filtration rate); Kaohsiung Medical University Hospital (KMUH); Food 
and Drug Administration (FDA); glycated hemoglobin (HbA1c); dipeptidyl peptidase-4 (DDP-4); low-density lipoprotein cholesterol (LDL-C); urinary albumin creatinine ratio (UACR); angiotensin-converting enzyme inhibitor (ACEI); angiotensin receptor blocker (ARB); cyclooxygenase-1 (COX-1); diabetic nephropathy (DN); high-density lipoprotein cholesterol (HDL-C).

\section{Author contributions}

Conceived and designed the study: M.Y.L., W.H.H., P.J.H., S.C.C. and S.J.S. Performed the study: W.H.H., M.Y.L., P.C.L. and S.C.C. Analyzed and collected the data: W.H.H., P.C.L. and S.C.C. Prepare Tables and Figure: M.Y.L. and S.C.C. Wrote the paper: W.H.H. and S.C.C. All authors reviewed the manuscript.

\section{ACKNOWLEDGMENTS}

The authors thank the help from the Statistical Analysis Laboratory, Department of Medical Research, Kaohsiung Medical University Hospital, Kaohsiung Medical University.

\section{CONFLICTS OF INTEREST}

The authors declare no conflicts of interest.

\section{GRANT SUPPORT}

The study was supported by a research grant from the Kaohsiung Medical University Hospital (Kaohsiung, Taiwan).

\section{REFERENCES}

1. Glucophage (metformin hydrochloride) and Glucophage XR (extended-release) prescribing information. Bristol, NJ: Bristol-Myers Squibb; 2009.

2. American Diabetes Association. 8. Pharmacologic Approaches to Glycemic Treatment. Diabetes Care. 2017; 40:S64-s74.

3. Peters N, Jay N, Barraud D, Cravoisy A, Nace L, Bollaert PE, Gibot S. Metformin-associated lactic acidosis in an intensive care unit. Crit Care. 2008; 12:R149.

4. DeFronzo R, Fleming GA, Chen K, Bicsak TA. Metforminassociated lactic acidosis: Current perspectives on causes and risk. Metabolism. 2016; 65:20-9.

5. Lipska KJ, Bailey CJ, Inzucchi SE. Use of metformin in the setting of mild-to-moderate renal insufficiency. Diabetes Care. 2011; 34:1431-7.

6. Inzucchi SE, Lipska KJ, Mayo H, Bailey CJ, McGuire DK. Metformin in patients with type 2 diabetes and kidney disease: a systematic review. Jama. 2014; 312:2668-75. https://doi.org/10.1001/jama.2014.15298.
7. Hung SC, Chang YK, Liu JS, Kuo KL, Chen YH, Hsu CC, Tarng DC. Metformin use and mortality in patients with advanced chronic kidney disease: national, retrospective, observational, cohort study. Lancet Diabetes Endocrinol. $2015 ; 3: 605-14$.

8. Tang SCW. Recent advances in managing and understanding diabetic nephropathy. F1000Res. 2016; 5.

9. Amador-Licona N, Guizar-Mendoza J, Vargas E, SanchezCamargo G, Zamora-Mata L. The short-term effect of a switch from glibenclamide to metformin on blood pressure and microalbuminuria in patients with type 2 diabetes mellitus. Arch Med Res. 2000; 31:571-5.

10. Kim J, Shon E, Kim CS, Kim JS. Renal podocyte injury in a rat model of type 2 diabetes is prevented by metformin. Exp Diabetes Res. 2012; 2012:210821.

11. Bell S, Farran B, McGurnaghan S, McCrimmon RJ, Leese GP, Petrie JR, McKeigue P, Sattar N, Wild S, McKnight J, Lindsay R, Colhoun HM, Looker H. Risk of acute kidney injury and survival in patients treated with Metformin: an observational cohort study. BMC Nephrol. 2017; 18:163.

12. Wang DS, Kusuhara H, Kato Y, Jonker JW, Schinkel AH, Sugiyama Y. Involvement of organic cation transporter 1 in the lactic acidosis caused by metformin. Mol Pharmacol. $2003 ; 63: 844-8$.

13. Owen MR, Doran E, Halestrap AP. Evidence that metformin exerts its anti-diabetic effects through inhibition of complex 1 of the mitochondrial respiratory chain. Biochem J. 2000; 348:607-14.

14. Stacpoole PW. Lactic acidosis. Endocrinol Metab Clin North Am. 1993; 22:221-45.

15. Bellomo R. Bench-to-bedside review: lactate and the kidney. Crit Care. 2002; 6:322-6.

16. Eppenga WL, Lalmohamed A, Geerts AF, Derijks HJ, Wensing M, Egberts A, De Smet PA, de Vries F. Risk of lactic acidosis or elevated lactate concentrations in metformin users with renal impairment: a population-based cohort study. Diabetes Care. 2014; 37:2218-24.

17. Chen W, Abramowitz MK. Metabolic acidosis and the progression of chronic kidney disease. BMC Nephrol. 2014; 15:55.

18. Phisitkul S, Hacker C, Simoni J, Tran RM, Wesson DE. Dietary protein causes a decline in the glomerular filtration rate of the remnant kidney mediated by metabolic acidosis and endothelin receptors. Kidney Int. 2008; 73:192-9.

19. Dobre M, Rahman M, Hostetter TH. Current Status of Bicarbonate in CKD. J Am Soc Nephrol. 2015; 26:515-23.

20. Miranda-Diaz AG, Pazarin-Villasenor L, YanowskyEscatell FG, Andrade-Sierra J. Oxidative Stress in Diabetic Nephropathy with Early Chronic Kidney Disease. J Diabetes Res. 2016; 2016: 7047238.

21. Brownlee M. The pathobiology of diabetic complications: a unifying mechanism. Diabetes. 2005; 54:1615-25.

22. Chen X, Wu R, Kong Y, Yang Y, Gao Y, Sun D, Liu Q, Dai D, Lu Z, Wang N, Ge S, Wang F. Tanshinone II Aattenuates 
renal damage in STZ-induced diabetic rats via inhibiting oxidative stress and inflammation. Oncotarget. 2017; 8:31915-22. http://doi.org/10.18632/oncotarget.16651.

23. Pirola L, Balcerczyk A, Okabe J, El-Osta A. Epigenetic phenomena linked to diabetic complications. Nat Rev Endocrinol. 2010; 6:665-75.

24. Horsburgh S, Robson-Ansley P, Adams R, Smith C. Exercise and inflammation-related epigenetic modifications: focus on DNA methylation. Exerc Immunol Rev. 2015; 21:26-41.

25. Milagro FI, Mansego ML, De Miguel C, Martinez JA. Dietary factors, epigenetic modifications and obesity outcomes: progresses and perspectives. Mol Aspects Med. 2013; 34:782-812.

26. Portela A, Esteller M. Epigenetic modifications and human disease. Nat Biotechnol. 2010; 28:1057-68.

27. Cuyas E, Fernandez-Arroyo S, Verdura S, Garcia RA, Stursa J, Werner L, Blanco-Gonzalez E, Montes-Bayon M, Joven J, Viollet B, Neuzil J, Menendez JA. Metformin regulates global DNA methylation via mitochondrial onecarbon metabolism. Oncogene. 2017.

28. Schaeffner ES, Kurth T, Curhan GC, Glynn RJ, Rexrode KM, Baigent C, Buring JE, Gaziano JM. Cholesterol and the risk of renal dysfunction in apparently healthy men. J Am Soc Nephrol. 2003; 14:2084-91.
29. Chen SC, Hung CC, Kuo MC, Lee JJ, Chiu YW, Chang JM, Hwang SJ, Chen HC. Association of Dyslipidemia with Renal Outcomes in Chronic Kidney Disease. PLoS One. $2013 ; 8$.

30. Abrass CK. Cellular lipid metabolism and the role of lipids in progressive renal disease. Am J Nephrol. 2004; 24:46-53.

31. Hattori M, Nikolic-Paterson DJ, Miyazaki K, Isbel NM, Lan HY, Atkins RC, Kawaguchi H, Ito K. Mechanisms of glomerular macrophage infiltration in lipid-induced renal injury. Kidney Int Suppl. 1999; 71:S47-50.

32. Ninomiya $\mathrm{T}$, Perkovic V, de Galan BE, Zoungas $\mathrm{S}$, Pillai A, Jardine M, Patel A, Cass A, Neal B, Poulter N, Mogensen CE, Cooper M, Marre M, et al. Albuminuria and kidney function independently predict cardiovascular and renal outcomes in diabetes. J Am Soc Nephrol. 2009; 20:1813-21.

33. Radcliffe NJ, Seah JM, Clarke M, MacIsaac RJ, Jerums G, Ekinci EI. Clinical predictive factors in diabetic kidney disease progression. J Diabetes Investig. 2017; 8:6-18.

34. Gradzki R, Dhingra RK, Port FK, Roys E, Weitzel WF, Messana JM. Use of ACE inhibitors is associated with prolonged survival of arteriovenous grafts. Am J Kidney Dis. $2001 ; 38: 1240-4$. 